\title{
QUESTÕES SOBRE A POLÍTICA DO "VIVIR BIEN" NA AMAZÔNIA
}

\section{INDÍGENA}

Juan Pablo Sarmiento Barletti - University of St. Andrews

\section{INTRODUÇÃO: A POLÍTICA COTIDIANA NA AMAZÔNIA INDÍGENA}

Parece que quando se trata das discussões sobre política e poder, os povos indígenas encontram-se em um dilema criado por uma definição limitada do que realmente conta como prática política no cenário político moderno. Tal limitação conduz a uma terrível miopia que se manifesta quando políticos, ativistas e analistas se deparam com atividades políticas que não se enquadram em seus moldes . Não estou argumentando, somente, em favor de uma visão semelhante à de Edward Said (1978), que afirmava que intelectuais europeus (ou euro-americanos) criam seus objetos de estudo através de discursos culturais específicos. Isso porque, apesar de importante, tal consideração não é suficiente. Diante do dilema colocado para as organizações políticas indígenas, elas são criticadas tanto por um uso inautêntico de alegorias políticas e legais euro-americanas em suas narrativas, quanto por perderem legitimidade e reconhecimento caso não sigam as imagens e expressões sobre identidade indígena que são esperadas pelos Estados e pelas organizações não governamentais. Desde essa perspectiva, as políticas entram em ação apenas em espaços nos quais os grupos indígenas são obrigados a perseguir seus interesses em domínios organizados pelo Estado, ou seja, travando lutas políticas focadas em categorias legais (Gledhill, 2000). Assim, faz-se necessário que os movimentos indígenas tenham seus direitos reconhecidos pelo Estado em previsões constitucionais. No que se refere à atividade política, como Beth Conklin e Laura Graham argumentaram, a identidade cultural amazônica constitui a fonte mais eficiente de poder político dos povos indígenas. No entanto, essemecanismo é eficiente "apenas enquanto as identidades políticas indígenas ressoem com ideias e símbolos ocidentais" e "coincidam com as preocupações globais e tendências do momento" (1995: 706).

No entanto, o dilema parece se resolver quando as organizações indígenas reconhecem as armadilhas da representação e os espaços existentes em diferentes contextos políticos passíveis de serem explorados de maneira vantajosa. Este ensaio se debruça sobre este dilema e compromete-se com a sua resolução ao olhar para as práticas políticas dos ashaninka, uma sociedade amazônica indígena no leste do Peru. Contudo, em vez de analisar as políticas das organizações, prefiro me atentar às formulações alternativas de ação política entre o povo ashaninka, como exemplificado pelo kametsa asaiki, a sua maneira de "vivir bien". Adescrição etnográfica e a análise dessas formulações apresentam um desafio crucial para as falsas suposições sobre o que constitui o próprio objeto do estudo da política indigenista. O povo ashaninka vivencia seus arranjos de conhecimentos em torno de práticas kametsa asaiki enquanto atos poderosos e cotidianos, responsáveis pela criação de seres humanos. Como veremos, é a prática política que cria 
o mundo em que eles vivem e que desafia as tentativas de controle sobre suas vidas. Diante disso, argumentarei que as práticas kametsa asaiki são práticas políticas que podem ser invisíveis para atores estatais e não-estatais que criam o dilema que eles enfrentam, mas têm resultados que são, sem dúvida, visíveis para todos.

Eu quero destacar o poder político envolvido nas práticas kametsa asaiki, principalmente devido à sua aparente fragilidade. Pierre Clastres (1987) criticou a antropologia política tradicional por ter universalizado a associação weberiana do poder político com coerção e subordinação. Ele postulou que os povos amazônicos não vivem em sociedades nas quais o poder político não existe, destacando o equívoco das suposições que universalizaram as formas de poder encontradas nas sociedades estatais modernas. Seguindo o exemplo de Joanna Overing, procurarei indicações e compreensões de poder, a partir de perspectivas indígenas, que sugiram que o poder é definido pelo conhecimento que dá vida(Overing 1985; 2008) e que poder político é aquilo que permite a produção social (Santos Granero, 1986a). Através da descolonizaçãoe indigenização do conceito de poder político, torna-se possível compreender a singularidade da política indígena.

\section{CONTEXTO ETNOGRÁFICO}

Os ashaninka pertencem ao tronco linguístico aruaque, existente na Amazônia Ocidental. Sua população é estimada em cerca de 100 mil pessoas, sendo que a maioria vive no Peru e cerca de 2 mil vivem no estado brasileiro do Acre. Sua produção está focada nos roçados, na caça e na coleta. Nas últimas décadas, essa forma de produção foi complementada com o dinheiro conseguindo com a agricultura comercial, a extração artesanal de madeira e o trabalho assalariado, principalmente a serviço de chefes mestizos e, mais recentemente, deoutros ashaninka. Os grupos ashaninka são conhecidos por serem ferozmente autônomos e igualitários e, de acordo como as descrições mais recorrentes, vivem em famílias baseadas no parentesco e relativamente afastadas umas das outras. Esta forma de organização social tem sido explicada de diferentes maneiras, às vezes pelas condições ambientais (Denevan, 1974) e, às vezes, como tentativa de garantir uma vida pacífica (Killick, 2005). No entanto, durante meu trabalho de campo (2007-2009) encontrei aldeias médias e grandes, onde viviam entre 400 e 1000 pessoas, com casas que foram construídas muito próximas umas das outras. Esta reorganização da vida social deve ser contextualizada pelo impacto que os conflitos armados no Peru (1980-2000) tiveram em suas vidas. Em 2003, a Comissão da Verdade e Reconciliação Peruana concluiu que, entre 1988 e 1994, cerca de 10 mil dos 100 mil ashaninka foram deslocados à força nos vales dos rios Ene, Tambo e Perené. Pelo menos 6 mil pessoas morreram e quase 5 mil estavam sob controle do Sendero. No entanto, até o final do ano seguinte a milícia indígena tinha resgatado 2.800 ashaninkas na região do Ene e, em 1993, havia resgatado mais de 1.000 na região do Tambo e do Perené. Eles foram levados para um dos cinco campos de refugiados internos criados pelo exército peruano nos rios Ene e Tambo, que se tornaram superpopulosos e que foram atingidos por uma sucessão de ataques, surtos de cólera e pela fome. Em outras áreas, a circulação de histórias sobre os excessos dos insurgentes maoístas suscitou grande temor em grupos ashaninka que recebiam parte das centenas de refugiados dos confrontos armados nos rios Ene e Tambo. Por tudo isso, ao longo das últimas três décadas, grupos familiares se mudaram para assentamentos nucleados, buscado a segurança que a vida em comunidade poderia assegurar. Paralelamente, também buscavam tirar proveito de escolas e postos médicos estabelecidos pelo Estado peruano nesses assentamentos. 
Viver em grandes aldeias torna-se mais complicado devido às preocupações ashaninka sobre o assunto. Acredita-se que um grande número de pessoas que vive em estreita proximidade inevitavelmente entrará em conflito. Os ashaninka têm vários mecanismos de prevenção de conflitos, como a sua preferência pela separação das partes conflitantes (Santos-Granero, 2000), mas não têm mecanismos próprios de resolução de conflitos. A situação, portanto, torna-se especialmente delicada na atualidade, quando a fissão já não é viável entre os moradores, que não somente querem continuar vivendo perto de escolas e postos médicos, mas têm suas casas construídas com materiais que são mais dificeis de mover e muito valiosos para deixar para trás, como madeiras e ferro corrugado. Os moradores também se envolvem com a agricultura comercial de longo prazo, como de café e de cacau, e também por essa razão não podem se mover sem prejudicar a continuidade de sua produção. Ao mesmo tempo, sua vida cotidiana é marcada pela pressão que o Estado peruano exerce sobre seu território através do seu sistema jurídico e das concessões para indústrias extrativistas, bem como para camponeses sem terra da região andina. As atividades de todos esses atores dificultam atividades de caça e de pesca. Assim, muitas comunidades ashaninka criadas após os conflitos armados são compostas de pessoas que lutaram em lados diferentes, criando populações estáticas de antigos inimigos que vivem nas proximidades. Curiosamente, mesmo que tenha sido uma pressão externa que os levou a viver em comunidades maiores, meus informantes ashaninka exaltam as vantagens oriundas de sua opção pela vida comunitária, sinalizando que essa reorganização social foi importante para satisfazer as necessidades que eles reconhecem como importantes para o kametsa asaiki hoje.

Kametsa asaiki significa "viver bem/harmoniosamente/pacificamente". Este modo de vida está relacionado com a fabricação de Ashaninkasanori (pessoas reais ashaninka) através do cumprimento e do ensinamento de três conjuntos inter-relacionados de conhecimento: (1) o controle das emoções antissociais (por exemplo, a raiva, o ciúme, a avareza e a tristeza) e, ao mesmo tempo, a prática de emoções socialmente construtivas (por exemplo, amor, felicidade e tristeza); (2) a adoção e demonstração de uma postura de trabalhadores dedicados, já que os Ashaninkasanori devem ser seres socialmente produtivos, que compartilham o produto de seu trabalho e que estão abertos para receber o produto do trabalho dos outros, compartilhando a felicidade que envolve todo o processo; e (3) a participação em relações de cuidados (por exemplo, alimentação, banho e proteção) entre as pessoas que se relacionam entre si como Ashaninkasanori. Uma parte importante dessas relações é a comensalidade e o apreço pelas substâncias socialmente produtivas (por exemplo, alimentos "reais" e plantas mágicas), evitando as negativas (por exemplo, o consumo excessivo de alimentos das pessoas brancas e o álcool). Este conjunto de conhecimentos tem relação com a dificuldade de criação de cuerpos fuertes e caras felices ashaninka (corpos fortes e rostos felizes ashaninka).

Os desdobramentos do conflito armado exigiram um esforço maior e mais explícito de sociabilidade, valor que notoriamente é parte da proposta do kametsa asaiki como um projeto moral comunitário. Isso se torna óbvio nas sessões de aconselhamento dadas a toda a comunidade pelos líderes comunitários antes de festas comuns e reuniões. Também fica evidente em outras ocasiões menos formais, tais como visitas domiciliares ou festas de bebida fermentada de mandioca, quando uma autoridade comum lembra os comuneros da necessidade de "vivir bien" ou, ainda, quando os próprios comuneros lembram aos outros que eles devem ensinar seus filhos a não roubar e devem ensiná-los como trabalhar e viver como um Ashaninkasanori. Como veremos, no contexto atual a criação diária de humanidade, 
relacionada com essas práticas e sua manutenção através do parentesco, toma forma de manifesto político contra as tentativas, promovidas por uma variedade de atores, de colocar os ashaninka no final de uma cadeia de relações hierárquicas e coercitivas. O problema é que essas práticas cotidianas não são percebidas como políticas, mesmo que os seus efeitos sejam percebidos como tal pelo Estado e por outros atores.

O movimento político indígena amazônico, no Peru, recentemente tornou-se o centro da política nacional, isso devido aos atos deploráveis da polícia durante a remoção violenta de manifestantes indígenas amazônicos (em 5 junho de 2009), que estavam bloqueando uma estrada fora da cidade de Bagua. O bloqueio foi parte de um protesto nacional organizado pela AIDESEP (Asociación Interétnica de Desarrollo de la Selva Peruana), a organização guarda-chuva da Amazônia indígena no Peru. Reagiam aos decretos, aprovados pelo então presidente Alan García, que colocavam seu direito à terra em risco ao favorecerem indústrias extrativistas. Os trágicos acontecimentos de Bagua foram rapidamente rotulados pela imprensa internacional como o "Tiananmen da Amazônia" devido ao número de mortes causadas pelos confrontos no dia. O protesto em Bagua não foi o único, já que grupos de povos indígenas em outros lugares bloquearam rios amazônicos, aeroportos e estradas. O governo de García tentou deslegitimar esses protestos, postulando que os indígenas amazônicos não eram capazes de tamanha organização e insinuando que a Venezuela e os setores da esquerda teriam tido influência no desenrolar dos eventos. Apesar disso, a dimensão massiva desses protestos evidencia as imprecisões das críticas sobre a ausência de um movimento político indígena no Peru. O Peru tem sido apontado como um caso especial na discussão acadêmica sobre política indígena latino-americana, já que os analistas têm destacado a ausência, fraqueza ou imaturidade de movimentos indígenas naquele país em comparação com aqueles seus vizinhos, Bolívia e Equador (Warren e Jackson, 2002; Albó, 2004; Yashar, 2005). Este argumento foi refutado por Shane Greene (2006), que relaciona esse tipo de crítica com a tendência das análises andino-centricas concentrarem-se na região dos Andes mesmo diante dos esforços organizativos que têm sido colocados em prática pelos indígenas amazônicos desde 1960.

AausênciaencontradanosAndes foi estendida para orestodopaís. Elamostrou, mais umavez, a "invisibilidade" que recai sobre a Amazônia, salvo algumas importantes exceções, nas discussões sobre política peruana realizadas por analistas que não compreendem a região. Esta "ausência" também foi refutada no que se refere à região andina. Marisol de la Cadena (2000), entre outros analistas que debatem o assunto, argumenta que existem movimentos indígenas cotidianos e bem-sucedidos que simplesmente não são reconhecidas como política étnica, tal como os de intelligentsia mestiza indígena. Mesmo assim, esta abordagem analítica é parte de uma tendência na qual sempre que os analistas querem saber mais sobre atitudes políticas ameríndias eles geralmente concentram-se nas elites. No caso daAmazônia, os estudos sobre política, poder e representação política concentram-se, embora por razões diferentes e com algumas notáveis exceções (por exemplo, Passes, 2004), nas vozes masculinas dos líderes das organizações ou dos chefes das comunidades (por exemplo, Brown, 1993).

Estudos sobre a prática política entre os ashaninka geralmente concentram-se nos homens e no seu poder como guerreiros, xamãs ou líderes políticos (por exemplo, Veber, 2009). Os homens é que foram treinados como os primeiros 
professores bilíngues, e também foram os líderes da milícia indígena contra o Sendero. Agora, majoritariamente, são os homens quem lideram as organizações. Geralmente, eles receberam educação formal e tiveram níveis mais elevados de exposição à sociedade nacional em relação a outros indígenas. Muitos desses líderes políticos indígenas surpreendem agentes estatais e não estatais em suas expectativas. Eles sobressaem em seus modos de representação política e ativismo, tornando-se agentes de cultura e tradutores das demandas dos povos indígenas. No entanto, as narrativas e metáforas apresentadas por esses líderes não correspondem à vida cotidiana local. Eu, por exemplo, participei de protestos locais em que os participantes pintaram seus rostos com tintas vermelhos nos padrões de guerra, vestiramse com roupas tradicionais e marcharam descalços pelas ruas cantando e produzindo sons altos e agudos associados à guerra. Em outros contextos, quando, por exemplo, solicitam verbas do governo regional, os líderes ashaninka em Satipo apelaram para o representante local a conceder-lhes o que eles acreditam que os ashaninka merecem enquanto vítimas do conflito armado peruano.

Assim, mesmo que as organizações políticas ashaninka utilizem essas imagens e narrativas previsíveis de guerra e/ou vitimização, elas não aparecem com destaque no nível da aldeia. Ao invés de narrativas universalizadas sobre vítimas ou guerreiros patrióticos, a vida cotidiana é criada através da busca do kametsa asaiki e da reconciliação promovida pela re-fabricação dos corpos de antigos demônios, que não são simplesmente convidados de volta à vida social humana. Assim, o kametsa asaiki não é sobre a universalização de narrativas de guerra ou vitimização, mas sobre seu poderoso conhecimento criador de humanidade. Notavelmente, e ao contrário de muitas políticas das organizações, o poder político no kametsa asaiki não é uma prerrogativa masculina, e pode ser promulgada tanto por homens quanto por mulheres . No entanto, fora do ambiente das comunidades essas práticas não são facilmente reconhecidas como políticas. É preciso explicar um pouco mais sobre o dilema que mencionei anteriormente para esclarecer esse argumento.

\section{O DILEMA DAS POLÍTICAS INDÍGENAS}

Alguns estudiosos afirmam que as organizações indígenas e suas conquistas servem, principalmente, para criar novas elites indígenas que seriam tão propensas a corroborar com empresas transnacionais quanto com ONG's (por exemplo, Dombrowski, 2002). Adam Kuper escreveu:

"O movimento dos povos indígenas tem sido promovido pela ONU, pelo Banco Mundial, por agências internacionais de desenvolvimento e organizações não governamentais. (...) Novas identidades são fabricadas e porta-vozes são identificados como sendo necessariamente não-representativos e podem ser, efetivamente, criações dos partidos políticos e das ONG's. Esses porta-vozes exigem o reconhecimento de formas alternativas de compreender o mundo, mas ironicamente o fazem na linguagem da teoria cultural ocidental. Já que as representações de identidade estão tão distantes das realidades locais, e já que a riqueza relativa das ONG’sé tão distinta das riquezas locais, é difícil que esses movimentos sejam democráticos." (2003: 395)

Como as reações ao provocante ensaio de Kuper atestam, sua crítica não reflete a história do movimento 
indígena, a discriminação que esses grupos sofrem e tampouco os casos de deslocamento forçado e de invasão que eles sofreram nas mãos de grupos dominantes (Niezen, 2003; Minde, 2008). Neste sentido, a contradição apontada por Kuper foi abordada a partir de uma perspectiva diferente, que destaca a astúcia política dos líderes indígenas nestas situações em vez de identificar o uso da "teoria cultural ocidental" por indígenas como um processo negativo. Muitos analistas enfatizam a capacidade de alguns líderes indígenas de articularem discursos de uma forma atraente para os organismos de financiamento (por exemplo, Jackson, 1995; Li, 2000; Conklin, 2002). Isso incluiria o uso de ideias sofisticadas sobre o conhecimento indígena e a construção de uma retórica sobre os povos indígenas como protoambientalistas. Acrítica de Kuper não éúnica, já que opositores do movimento indígena criticam sua suposta hipocrisia, focando suas críticas nas contradições entre a retórica e a ação, a fim de desacreditar as reivindicações indígenas aos recursos ambientais (ver Rubenstein, 2004, para uma discussão sobre essas críticas).

No entanto, os líderes indígenas perdem legitimidade ou reconhecimento caso não consigam corresponder aos padrões de "autenticidade" da cultura tradicional estabelecidos por patrocinadores governamentais ou nãogovernamentais (Conklin e Graham, 1995), ou àquilo que é esperado em sociedades multiculturais neoliberais (Povinelli, 2002). No caso da Amazônia peruana, a importância de atender a essas expectativas tornou-se evidente quando a AIDESEP passou a ser demonizada pelo governo peruano, após os eventos de Bagua, em favor de alianças com o CONAP (Confederación de Nacionalidades Amazônicas do Peru), uma organização historicamente menos representativa. O reconhecimento oficial tem o efeito de distinguir os elementos "legítimos" dos "radicais" nos movimentos, recompensando "organizações que promovem demandas aceitáveis sobre direitos culturais e [punindo] os outros" (Hale, 2002: 498). Neste caso, o Estado reconhece o CONAP como um interlocutor "legítimo", enquanto a AIDESEP é considerado demasiada "radical" devido a sua participação nos eventos em Bagua. Estas diferentes abordagens eram óbvias no início deste ano durante uma reunião de representantes da maioria das organizações guarda-chuva indígenas peruanas que se encontraram para debater a Lei de Consulta. Esta lei estava sendo debatida no Congresso peruano na época, honrando as resoluções da Convenção sobre os Povos Indígenas e Tribais de 1989 (OIT,169), ratificadas pelo Peru em 1994. Essa legislação regulamenta a maneira pela qual o governo vai consultar os grupos indígenas antes de desenvolver novas legislações ou concessões para projetos que afetem suas vidas, territórios ou direitos. Na reunião e nos comunicados de imprensa que se seguiram, a AIDESEP, que havia sido apresentada pelo Estado como a culpada pelos atos violentos em Bagua, exigiu a modificação de partes importantes da lei, especificando que ela não poderia ser aplicada retroativamente. O CONAP apoiou a proposta textual do governo, argumentando que eles estavam "dispostos a discutir" desde uma "posição proativa e positiva”, em oposição à atitude da AIDESEP que teria sido conduzida por "interesses políticos" e que estaria agindo "intransigentemente e sem vontade de discutir" . AAIDESEP insistiu na modificação de seções da lei que "não seguiam o espírito da Convenção 169 da OIT ou da Declaração da ONU [para os Povos Indígenas].

No entanto, os próprios povos indígenas começam a resolver os dilemas que enfrentam quando identificam as armadilhas da representação e os diferentes níveis de identidade (local, regional, nacional e transnacional) que podem ser articulados e re-articulados de acordo com os interlocutores, a situação em questão e os outros atores envolvidos. 
Para entender esses processos, Charles Hale destaca conceito de el índio permitido, o "índio permitido", de Silvia Rivera Cusicanqui. Rivera cunhou este termo como uma maneira de falar sobre "como os governos estão usando os direitos culturais para dividir e domesticar os movimentos indígenas" (Hale, 2004: 17). A caracterização de Hale do "índio permitido" é muito útil nesse momento. Para ele o "índio permitido" é um modo de ser indígena no qual "alguns direitos podem ser desfrutados com a condição implícita de que outros não surgirão" (2004: 18). Neste tipo de situação o Estado permite que os povos indígenas participem de atividades políticas, mas apenas enquanto estas atividades não representem uma ameaça para a ordem estabelecida. Isso, no entanto, não exclui a possibilidade de que essas mesmas pessoas possam recorrer a práticas “indígenas (não) permitidas” em outros contextos, e vice-versa .

A crítica de Rivera aponta para uma saída do referido dilema: etnografias dos agentes de Estados (como as Nações Unidas e ONG’s) que atuam como intermediários culturais, capazes de repaginar noções burguesas de direitos e oferece-las ao consumo indígena. Quero sugerir outra saída, inspirada por discussões com o falecido Steven Rubenstein sobre a análise Dan Rosengren acerca das identidades coletivas na Amazônia indígena. Seguindo Gilles Deleuze e Félix Guattari(1988), Rosengren argumenta que indígenas amazônicos podem seguir dois modelos distintos de construção da identidade. O primeiro é o modelo "raiz principal", e insiste na "origem como única e na cultura como identidade com etnicidade" (2003: 223). Esse modelo pode até utilizar a autodeterminação indígena, mas de uma maneira que concorda:

“(...) com noções geopolíticas ocidentais que assumem a existência de um vínculo orgânico entre as pessoas, lugar e linguagem. Esta perspectiva adquiriu aceitação geral ao ter sido tomada como certa por missionários, cientistas e burocratas das administrações nacionais - figuras cuja hegemonia intelectual facilitou a naturalização do que é essencialmente um sistema arbitrário". (Rosengren 2003: 222-223)

Rosengren está descrevendo a forma coletiva do "índio permitido", um tipo ideal que coincide com a caracterização de Kuper sobre a “teoria cultural ocidental” no movimento indígena contemporâneo.

Rosengren ainda argumenta que a autodeterminação também pode ser entendida em termos das cosmologias locais, por meio de um segundo modelo de identidade, um "rizoma" no qual "a identidade é formada em um processo de identificação relacional não limitado e expansivo, com múltiplos pontos de enraizamento" (2003: 223). Poderíamos chama-lo, o "índio (não) permitido", de um modelo de identidade coletiva e de ação que pode não ser visível para o Estado ou seus agentes, incluindo ONG's e defensores dos direitos indígenas . Rosengren coloca que o destaque dado pelas organizações aos grupos indígenas como "grupos étnicos delimitados, cujos membros compartilham interesses comuns e exclusivos, está em nítido contraste com a ênfase no local, comunidade 'não imaginada' onde as relações concretas são o que importa" (2003: 224). Assim, a principal diferença entre esses modelos é que o modelo raiz principal “ébaseado em noções de exclusividade e assimetria social, enquanto o modelo rizomático está associado a uma filosofia social de inclusão e simetria social" (2003: 223-224). O rizoma, por sustentar o igualitarismo e a autonomia, desafia a ordem existente ao questionar a premissa sobre a qual ela é construída: poder coercitivo assegurado pelo Estado. Subvertendo essa ordem, as práticas rizomáticas subvertem o Estado, pois, como veremos, desde uma perspectiva 
amazônica o poder está no conhecimento criador de seres humanos e só é legítimo quando está disponível para todos os que o querem.

No entanto, há uma divisão entre as análises das estruturas do tipo "raízes principais" que as chamam de "políticas", e as análises das estruturas rizomáticas que as rotulam como "culturais". Mas e se as práticas rizomáticas são políticas, mas de uma forma que não é visível de fora das sociedades indígenas amazônicas? E se elas realmente têm efeitos políticos que são visíveis para as ONG’s e para o Estado? Gostaria de refletir sobre como essas complicações são manejadas no nível local, e por isso apresento, brevemente, um exemplo relacionado com o fracasso de um projeto de desenvolvimento em uma comunidade ashaninka no baixo Urubamba, na Amazônia peruana. ONG’s, funcionários do Estado e muitos mestizos da região interpretaram esse fracasso como resultado da preguiça indígena supostamente inata. O caso, no entanto, é bem mais complexo do que parece quando o observamos cuidadosamente. Atentando para o que aconteceu descobrimos que os rizomas estão exercendo uma força que, subvertendo a formação do Estado em seu grupo, subverteu os próprios projetos.

\section{O PROJETO FORIN NO BAIXO URUBAMBA}

O FORIN (Proyecto Forestal Indígena) foi um projeto financiado pela União Europeia e coordenado por um grupo de ONG's ambientalistas, liderado pela WWF Peru e pela AIDESEP. Oficialmente, ele foi introduzido a fim de "reforçar a capacidade de gestão das comunidades indígenas, consolidando a segurança territorial e jurídica para desenvolver planos de manejo para produtos florestais". Este projeto foi uma oportunidade para que as comunidades indígenas pudessem extrair e vender madeira legalmente e por conta própria, conseguindo um bom lucro, em vez de vendê-la ilegalmente por pouco dinheiro e com o risco de tê-la confiscada pelo Estado. Citando um engenheiro florestal que trabalha no projeto, o FORIN ofereceu às comunidades locais "suporte para que possam produzir seu próprio capital... trabalhar em um lugar... legalmente, sem entrar em conflito com a lei”. O FORIN pagou pelos materiais e pelo processo técnico necessário para que uma comunidade pudesse extrair e transportar sua madeira para Pucallpa, a capital regional. No entanto, alguns desconfiavam desta súbita mudança de posição, já que os representantes do governo geralmente tentavam impedi-los de cortar madeira. Isso, no entanto, não significa que o projeto não fosse de interesse dos ashaninka que viviam nessas comunidades. Participei de uma reunião comunal em que o chefe da aldeia e um representante da OIRA(Organización Regional Indígena Atalaya), a organização guarda-chuva local, convidou os comuneros, através de um discurso apaixonado, a participarem do projeto. Ao concluir o discurso ele afirmou:

'Devemos acordar... aprender a vender nossos próprios recursos, parar de ser roubados. FORIN quer nos alertar, para que nós trabalhemos com salários justos... É triste que muitas aldeias estejam sendo sancionadas pelo governo, elas vão ter que pagar grandes [multas]. Temos de trabalhar, como [FORIN] diz, legalmente!"

OFORIN foi um sucesso nas comunidades com líderes que não ditavam trabalho ou tratavam os trabalhadores da mesma maneira que o fazem os patrões brancos ou mestizos. Em vez disso, esses líderes seguiram a abordagem kametsa asaiki do trabalho comunitário: estimulando práticas produtivas que respeitassem seu enfoque igualitário e 
autônomo. Estes não eram líderes coercivos dizendo às pessoas o que fazer. Ao contrário, eram líderes que ofereciam bebida fermentada de mandioca e que mantinham as pessoas entretidas, permitindo que os trabalhadores trabalhassem de acordo com suas vontades.

Nueva Esperanza, uma comunidade na região do baixo Urubamba, passou por uma experiência terrível com o FORIN.Opovoado perdeu dezenas demilharesdesoles emmadeira, queacabaramapodrecendojá queos trabalhadores a abandonaram a meio caminho do rio Ucayali. Tal atitude foi atribuída ao chefe local, Luis, e à sua tentativa de impor uma hierarquia através do poder coercitivo, comportando-se como um chefe madeireiro. Em vez de distribuir a comida que a comunidade havia recebido do FORIN, por exemplo, ele separou os melhores alimentos para si e os levou para casa. Pior ainda: enquanto os moradores da comunidade haviam sido informados de que o projeto iria lhes permitir bons salários sem lhes obrigar a trabalhar todos os dias, Luis estava fazendo o oposto e publicamente criticou aqueles que não se juntaram a ele, chamando-os de irresponsáveis por não quererem o melhor para sua comunidad e exigindo que aqueles que não quisessem trabalhar deixassem o povoado. Um ex-chefe comentou durante uma rodada de bebida fermentada de mandioca que sucedeu uma assembleia:

'Ele não sabe como falar... Quando eu era chefe eu sabia que alguns poderiam vir trabalhar um dia e outros no outro dia. Todo mundo tem suas próprias responsabilidades... Não podemos forçar as pessoas a trabalharem, como fazem os patrões. Ele não pode simplesmente gritar com todo mundo. Quando será que esse menino vai aprender!"

Aqueles participantes do FORIN estavam seguros de mostrar o seu descontentamento, preferindo perder seus salários a trabalhar com uma figura tão antissocial. A princípio, quarenta e oito homens apareceram para cortar e transportar madeira, mas uma semana depois quinze homens já haviam desistido. Até o início do segundo mês apenas o chefe, seus irmãos, sobrinhos e outros poucos homens continuaram trabalhando. O consenso foi de que a maioria não queria participar porque ele se comportava como um patrão, gritando e insultando as pessoas durante acessos de raiva e, além disso, era preguiç̧oso, não contribuindo com o trabalho. Assim, seu comportamento desconsiderava duas vezes as normas de convívio kametsa asaiki. Chato, um morador que pediu demissão depois de duas semanas de trabalho, me relatou:

“Aqui nós trabalhamos nos nossos roçados pacificamente... não é como com um patrão que não faz nada, que só grita com você, te dizendo o que fazer... "vá trazer água"... Ninguém lhe diz o que fazer, você pode descansar, beber bebida fermentada de mandioca e, em seguida, voltar para a sua casa para comer com sua família. O que há de errado com aquele cara, ele é louco ? Se eu quisesse trabalhar para um patrão eu estaria trabalhando para um madeireiro em Inuya!"

Luis estudou até o ensino secundário e ocupou diferentes cargos em organizações locais. Seria tentador concluir que suas ações antissociais eram consequência do tempo que ele viveu longe da comunidade (como acreditam alguns outros moradores) e, portanto, influenciadas por uma forma diferente de liderança e de compreensão sobre a produção econômica. No entanto, também podemos interpretar esta situação como um choque entre diferentes concepções de pertencimento e de responsabilidade, já que a comunidad não coincide com a unidade econômica tradicional, isto é, a 
família alargada ou uma comunidade familiar.

Luis sustentou que todos os comuneros tinham que participar do FORIN já que tinham Nueva Esperanza como sua comunidad nativa, um tipo de vínculo a um grupo baseado na vida dentro de um espaço legalmente criado: a identidade no modelo de "raiz principal". No entanto, aqueles que abandonaram o projeto expressaram uma concepção de pertença e de lealdade a um grupo que não é baseada na residência comum dentro de um território, mas na comunidade rizomática constituída dentro dessas fronteiras por acidente histórico. Aqueles que permaneceram trabalhando com Luis eram seus parentes próximos, outro grupo com base em fundamentos rizomáticos, ou homens que queriam participar do projeto porque a madeira era de propriedade de la comunidad e por isso eles tinham o direito obter lucros enquanto comuneros, uma identidade no modelo "raiz principal". Durante rodadas de bebida fermentada de mandioca, muitos destes últimos sujeitos se queixaram que Luis não sabia como "vivir bien", mas decidiram que, como ele havia sido colocado no comando do projeto, teriam que continuar a trabalhar esperando que ele fosse substituído.

Acompanhando a literatura que trata sobre liderança, prevenção da liderança coercitiva e criação de estrutura na Amazônia indígena (por exemplo, Rosengren, 1987), podemos ver que essas reações dos ashaninka visam garantir o igualitarismo dentro de suas próprias relações políticas, impedindo que Luis pudesse atuar como um tirano. Quando Clastres afirma que as sociedades amazônicas são “contra o Estado" ele não estava se referindo a uma recusa explícita de um Estado específico, mas à luta diária contra a criação de um Estado: contra a imposição de hierarquias e de uma autoridade coercitiva dentro de suas sociedades. Isso é possível através de práticas cotidianas que demonstrem respeito por um ethos igualitário e pela autonomia de todos do grupo, impedindo, como nesse caso, o aparecimento de tiranos coercitivos entre eles (ver Santos-Granero, 1986b para uma crença semelhante entre os vizinhos yanesha). Há casos em que o tirano é mais difícil de conter, como no caso do Estado peruano, mas a ênfase colocada nas relações igualitárias entre os seres humanos "reais" segue funcionando em alguma medida.

Em um estudo semelhante sobre grupos de homens trabalhadores, Evan Killick (2007) descreve como os asheninka com os quais ele trabalhou recusavam-se a reconhecer a liderança de qualquer homem asheninka durante o transporte de madeira, mesmo que a falta de um coordenador complicasse ainda mais a tarefa. No entanto, esses mesmos homens seguiam com satisfação a liderança de um chefe madeireiro mestizo, e inclusive elogiavam sua capacidade de coordenar a atividade de uma maneira que eles jamais fariam. Isso funcionou, Killick comenta, porque ao seguirem um estranho os homens evitavam que diferenças entre iguais fossem criadas. Mesmo assim, o ensaio de Killick perde um ponto importante: enquanto no primeiro exemplo os homens asheninka estavam ajudando um colega também asheninka a transportar madeira, aqueles que trabalhavam com o chefe mestizo estavam sendo pagos pelo seu trabalho, o que de acordo com a prática local significa o recebimento adiantado de parte do pagamento. São dois tipos muito diferentes de relações de trabalho. Sei de casos em que os ashaninka trabalham para outros comuneros em troca de dinheiro, e nessas situações eles fazem o que é pedido e têm um prazo específico para terminar o trabalho. Situações como essa são extremamente diferentes das festas minga de trabalho comunitário, quando alguém recebe um grupo de 
pessoas por um dia e em troca trabalhará na minga de outras pessoas. Nestes casos, os homens nunca são incomodados ou ordenados. Na verdade, uma vez ouvi comentários sobre um homem que não estava satisfeito com os resultados da sua minga: "Bom, o que é que ele queria? Não é como se estivesse nos pagando! Ele não é meu patrão". O caso do FORIN é complicado em comparação com esses dois tipos de trabalho, porque os trabalhadores só recebem seu pagamento depois que a madeira foi vendida. Antes disso, entretanto, já tinham que seguir o calendário aprovado por Luis e obedecer as suas instruções, já que ele tinha sido colocado no comando pelo escritório do FORIN em Atalaya.

Gostaria de sugerir que as reações eram contra a criação forçada de uma estrutura dentro de uma sociedade igualitária. Assim como o Estado força a eleição de determinadas pessoas enquanto representantes legais da comunidad, o FORIN determinou Luis como responsável por aquele projeto, e por isso os dois casos representam a influência externa na vida local. Trata-se de uma espécie de poder que facilmente pode converter-se em abusivo, especialmente no que se refere à firma de negócios obscuros com patrões madeireiros locais. Os grupos ashaninka com os quais trabalho lidam com situações como essa de maneira igualitária, compartilhando a posição de representante da comunidade com qualquer pessoa interessada (a cada dois anos o posto é ocupado por outra pessoa) e, assim, criando uma série de autoridades comunais (Nueva Esperanza tinha trinta e seis postos de liderança diferentes) para assim compartir o poder e as responsabilidades com o maior número possível de pessoas. A reação aos excessos de Luis durante o FORIN e a forma como eles lidam com a criação de autoridades reflete as formas complicadas e múltiplas pelas quais os indígenas amazônicos entendem a rearticulação de lideranças e também reflete o quanto isso depende do contexto .

Mais tarde eu ouvi pessoas não-indígenas que observavam o projeto comentando sobre quão preguiçoso e problemático o povo de Nueva Esperanza tinha sido, pois preferiam beber bebida fermentada de mandioca, jogar futebol ou trabalhar em roçados que não produziam lucro em vez de terminar o trabalho com o qual a sua comunidad tinha se comprometido. $\mathrm{O}$ fato de que algumas comunidades foram bem sucedidas e outras não, mostra que os ideais do kametsa asaiki subvertem tanto as imposições do Estado quanto a hierarquia e o poder coercitivo envolvidos em suas práticas. O protesto teve um resultado óbvio, o fracasso do projeto. Pessoas de fora da comunidade preferiram interpretar esse resultado como consequência da preguiça ao invés de reconhecerem o protesto como ação política. Como analista, o que podemos tirar disso tudo? O que é este comportamento construído a partir do rizoma?

Apesar da complexidade e das fronteiras porosas entre os binômios "raiz principal"/rizoma e índios "permitidos"/“não permitidos", eles ainda são tipos ideais bons para pensar. A reação do povo ashaninka que vive em Nueva Esperanza ao projeto FORIN mostra que mesmo que o rizoma seja construído no nível local, isso não significa que a raiz esteja ausente em comunidades ou, ainda, que todas as práticas cotidianas no rizoma sejam do "índio não permitido". Como vimos, esses modelos de identidade não representam dois tipos distintos de pessoas, mas são diferentes modos de ação estratégicos, através dos quais os povos indígenas criam a identidade do grupo em diversos níveis e que podem ser usados para envolver a ordem política e as hierarquias criadas pelo Estado.

Mesmo que tenham resultados visíveis, o propósito por trás das práticas rizomáticas e de "índios (não) permitidos" fica difícil de ser compreendido caso não seja relacionado com as visões de mundo desses povos. Isso 
porque a compreensão dessas práticas requer um exame e uma compreensão holística de como relações de associação são criadas através da interação cotidiana. No caso ashaninka, podemos desenvolver essa análise a partir da observação das práticas kametsa asaiki, que provam que ser uma pessoa ashaninka não é uma característica inata de pertencimento, mas uma posição ocupada por seres cujo comportamento social segue um conjunto distinto de práticas. Neste contexto a humanidade não é um dado, mas um processo de fabricação. Da mesma maneira, a adesão ao grupo ashaninka local é o produto de uma capacidade histórica e de uma vontade de socializar.

\section{VIVER BEM COMO UM ASHANINKASANORI ("PESSOA ASHANINKA REAL")}

Práticas kametsa asaiki são práticas políticas voltadas para a fabricação de seres humanos "reais". Eduardo Viveiros de Castro (2001) propõe que, a partir de uma perspectiva amazônica, enquanto a afinidade e a afinidade potencial são supostas, a consanguinidade é o resultado de processos culturais. Isto significa que a adesão às redes de parentesco e ao grupo local não é dada, mas deve ser criada através de lembranças de atos cotidianos de cuidado e carinho (Gow, 2000) praticados pelos ashaninka em sua busca pelo kametsa asaiki. Isso é feito através de um processo bem informado de transformações corporais controladas, já que as ontologias indígenas amazônicas postulam que o corpo é inerentemente transformável e instável.

AparecidaVilaça(2002:351)explicaqueparaos Wari(daAmazôniabrasileira) “oquepermiteapermutabilidade do corpo é precisamente a equivalência dos espíritos: todos são igualmente humanos, igualmente sujeitos". Nesse mesmo sentido, meus informantes ashaninka postulam a ideia de que há um tipo de alma (um tipo de cultura) mas muitos tipos corpos (muitas naturezas) entre uma variedade de seres que, acredita-se, poderiam se encaixar na categoria de humanos. Todos os seres considerados detentores de uma alma (i/oshire, 'coração/alma/pensamentos dele ou dela') podem se diferenciar no corpo (espécie), mas ainda consideram a si e aos outros como sendo humanos.

Então, por exemplo, tanto ashaninkas quanto queixadas (Tayassu pecari) consideram-se como seres humanos, já que ambos têm alma e seguem práticas culturais humanas - como viver em grupos, trabalhar em conjunto, cuidar de seus filhos, fazer festas com bebida fermentada de mandioca, comer com seus parentes, ter xamãs, etc. No entanto, embora suas práticas culturais sejam as mesmas os seus corpos e seu ponto de vista, o que inclui a forma como eles veem a si mesmos e aos outros, são diferentes. Ashaninkas se veem como humanos e veem queixadas como queixadas (ou seja, como uma presa). Já os queixadas, devido ao tipo de relação social estabelecida, se veem como categoricamente humanos, mas veem os membros ashaninka da espécie humana como jaguares (ou seja, como predador). Os ashaninkas veem a bebida fermentada de mandioca como bebida fermentada de mandioca, mas os queixadas veem as poças de água barrenta como bebida fermentada de mandioca, usadas em suas festas.

Vilaça continua apontando que, "através da modificação da alimentação do corpo, da mudança de hábitos e do estabelecimento de relações sociais com outros sujeitos, outro ponto de vista é adquirido: o mundo passa a ser visto através do ponto de vista dos novos companheiros, isto é, os membros de outras espécies" (Ibid.). Se um ashaninka vive entre os brancos (Santos-Granero, 2009) ou entre queixadas (Gow, 2001), se come sua comida e participa de sua 
vida social, seu corpo iria se transformar no corpo de uma pessoa branca ou de um queixada; passaria a enxerga-los como similares e deixaria de ver seus ex-parentes como parentes. O oposto também é verdadeiro. Uma pessoa de fora que bebe bebida fermentada de mandioca, come carne de caça e peixe entre os ashaninka e que participa de atividades sociais (desde festas de bebida fermentada de mandioca até mingas) torna-se "igual" a eles. Pelo menos é o que me disseram que tinha acontecido comigo quando, no final do meu trabalho de campo, as pessoas repetidamente me diziam que "ya eres como ashaninka, Juanito" (você já é um ashaninka, Juanito). A maioria dos discursos em minha festa de despedida eram relações do que eu tinha comido, bebido e feito com quem discursava ou como parte de um grupo que tínhamos formado (ver Sarmiento Barletti, 2011) e assim relatavam como através dessas atividades eu tinha aprendido a viver de acordo com o kametsa asaiki na comunidade. Considerando que entre os povos amazônicos o ponto de vista está localizado no corpo (Viveiros de Castro, 1998), os ashaninka trabalham duro para fabricar corpos especificamente ashaninka entre os que os rodeiam, para assim garantir a estabilidade do seu ponto de vista e a possibilidade de que possam ver uns aos outros como parte de uma comunidade.

O fato que os discursos incluíam as atividades produtivas nas quais eu tinha participado é significativo. As pessoas que se consideram Ashaninkasanori, e que se relacionam entre si como tal, constantemente criam redes de relacionamento baseadas em experiências cotidianas como a organização do trabalho, a produção conjunta e o partilhar da comida. Assim, kametsa asaiki é um processo relacional e não uma busca individual. Na verdade, essa maneira de viver não tem relação com o fato de que "eu viva bem" e, antes, com o fato de que em um lugar ou em um povoado “as pessoas vivam bem”. Assim, "vivir bien" e ser um ashaninka no nível rizomático só pode ser conquistado através da relação com os outros em um lugar e um momento específico. Isso evidencia a importância da sua relação com o ambiente fisico em que praticam sua humanidade e desenvolvem relações sociais comunitárias e, ao mesmo tempo, enfatiza o rizoma, o lugar "local" em que os seres representam e criam a humanidade.

Estas transformações podem ter conotações mais macabras. As transformações daqueles que, acredita-se, tornaram-se demônios durante o conflito armado peruano, foram confirmadas pela alteração comportamental que seria decorrente da mudança de perspectiva ocorrida quando eles teriam sido alimentados com carne humana enquanto viviam entre os Sendero cadres, que seriam demônios. Como não haviam mudanças físicas evidentes, o que confirmou a mudança foi a transformação de sua perspectiva moral. Adquirir a perspectiva de um demônio os impedia de ver aos seus ex-parentes como pessoas, e por isso eles foram capazes de mata-los e tortura-los: eles viam os seus ex-parentes como presas. No entanto, assim como a humanidade é um estado transitório entre muitos outros, ser um demônio também o é. A reconciliação pós-conflito é um processo que ajuda esses demônios a reconquistarem seus corpos humanos, esquecerem-se da violência e abraçarem o kametsa asaiki ao voltarem a participar das redes de parentesco. A importância da arte de manter uma rede de parentesco boa e bela torna-se mais clara quando alguém em uma rede estreita de parentes se torna o "outro" perigoso durante a guerra, por exemplo.

Os ashaninka postulam que uma parte importante da criação dos seres humanos tem a ver com habilidades que transformam os seres em humanos sociais produtivos. Aqueles que vivem em uma comunidade estão continuamente 
envolvidos em um processo de criação mútua, já que todo o trabalho produtivo de uma pessoa contribui para que os membros de uma mesma comunidade sejam dotados de vida. Isso não inclui apenas o trabalho físico nas roças (produzindo mandioca e outros bens), a caça e a pesca (para fornecer carne de caça e peixe para consumo próprio e para redistribuição) ou mesmo o trabalho assalariado (para chefes madeireiros ou trabalhando na colheita de agricultores locais). Inclui, também, o trabalho cuidadoso envolvido na transmissão de conhecimentos para as crianças sobre as emoções socialmente produtivas (felicidade, amor e pesar) e sobre o controle das emoções negativas (o ciúme, que leva à raiva, que leva à violência), ensinando-os sobre práticas corporais (comer o alimento certo, saber fazer pintura facial, tomar banho de plantas específicas, curar-se através do vapor) e ensinando-os, também, que a ingestão das substâncias corretas que thes dará corpos fortes. Essas habilidades não são apenas repassadas através do exemplo, mas são práticas ensinadas através do mito, de sessões de aconselhamento entre pais e filhos e através da participação em rituais.

Assim, a humanidade está na maneira de se relacionar com os outros. A identidade humana é no corpo, mas se o corpo for tomado como certo e não for construído constantemente, ele vai degenerar. Dessa maneira, a manutenção da condição Ashaninkasanori só é possível através de práticas kametsa asaiki: o comportamento, ao mesmo tempo, cria e confirma a identidade do ser humano.

\section{CONCLUSÃO}

A criação dos seres humanos ashaninka no rizoma, através de práticas kametsa asaiki, evidencia o lado "não permitido" da prática política ashaninka. Não estou alegando que o todo da vida cotidiana nas comunidades ashaninka sejam práticas do "índio (não) permitido", ou que o cotidiano não tenha conexões com a "raiz principal". Estes tipos ideais tornam-se diferentes posições políticas a partir das quais se pode participar da indigeneidade e ferramentas úteis com as quais se pode pensar. É por isso que aqueles que constroem identidades locais rizomáticas no cotidiano podem, quando necessário, se incluir em uma identidade ashaninka do tipo raiz principal - por exemplo, quando apoiam as lutas de suas organizações políticas em defesa do seu direito de manter o modo de vida que desejam. Da mesma forma, 
como observamos com o caso do projeto FORIN, as pessoas podem defender seus direitos como membros de uma comunidade, uma ideia ligada ao modelo raiz principal de pertença, mas, em seguida, podem trabalhar em grupos baseados no parentesco, que concebe o pertencimento em um nível rizomático.

Muitos dos meus informantes ashaninka acreditam que Alan García, presidente do Peru entre 1985-1990 e 2006-2011, queria matá-los quando enviou o Sendero na década de 80 ou quando, em seu segundo mandato, permitiu a entrada das empresas petrolíferas na região . Na verdade, muitos dos meus informantes referiam-se ao presidente como ashitarori kityoncari/compania, "o dono/mestre dos vermelhos/as companhias". Eles estavam convencidos de que ele só queria matá-los porque nunca os tinha visitado e que havia percebido que eles realmente "viviam bem". Essa suspeita em relação a García foi confirmada, primeiramente, por um artigo publicado no jornal "El Comercio" com o título de Perro del Hortelano, no qual ele condenava aquilo que percebia como o uso ocioso das terras indígenas amazônicas. Em seguida, o anúncio presidencial sobre a construção de uma barragem em Pakitzapango, no rio Ene (região povoada por muitos ashaninkas) também ratificou a desconfiança dos indígenas. Mas o que realmente importa é que mesmo se ele os tivesse visitado teria sido incapaz de observar a maneira bem sucedida pela qual criavam seu modo de vida desejado e resistiam às tentativas de agentes estatais e não-estatais de impedir essa criação.

A organização social contemporânea nas comunidades mais populosas que se deparam com uma série de limitações territoriais traz novas pressões para a vida cotidiana dos povos ashaninka quando comparada com os dispersos assentamentos de base familiar que existiam há menos de cinquenta anos. Essa situação é originada pelo Estado, pelas indústrias extrativistas, pelas invasões de terras e, também, por aqueles ashaninka que são considerados como pessoas que "não sabem viver bem”. Como no caso de Luis, durante o projeto FORIN, estas são pessoas que agem violentamente contra seus parentes, que participaram do Sendero durante os conflitos armados no país, que abusam de sua posição de porta-vozes para obter lucro pessoal ou para criar situações em que possam exercer poder de coerção sobre os outros. Como também vimos no caso FORIN, a vida cotidiana é tumultuada por aqueles que defendem um modelo do tipo "raiz principal" de pertencimento para criar um novo espaço político, a comunidad nativa, para em seguida estabelecer novas obrigações para os seus membros, como a participação em trabalhos comunitários e as contribuições monetárias às atividades da comunidad . Apesar disso, a busca do kametsa asaiki torna-se uma declaração em favor da humanidade e um modo distinto de interação social igualitária. Ela prova que, em última instância, o kametsa asaiki é o argumento ashaninka em uma luta para decidir "o que faz com que a vida mereça ser vivida". Através disso mostram que "no fim, então, a política é sobre o significado da vida" (Graeber, 2001: 88).

Projetos indígenas de "viver bem", como o kametsa asaiki, recentemente têm estado em primeiro plano nos debates políticos em alguns países da América Latina, especialmente na Bolívia e no Equador. A constituição equatoriana 2008 inclui o buen vivir como um direito. Alguns artigos da referida Constituição inclusive apresentam o sumak kawsay como sinônimo de buen vivir, criando um problema de homonímia (visto que conceitos de contextos muito diferentes são usados como sinônimos quando eles não têm o mesmo significado). Dizer que o buen vivir neste contexto respeita as visões de mundo indígenas é generalizar projetos de "viver bem" de muitos grupos diferentes, 
os apresentando como um mesmo conceito ideológico. Mesmo que este projeto tenha provado ser baseado na acumulação de riqueza capitalista através da extração destrutiva dos recursos naturais em detrimento de narrativas de progresso coletivo anti-capitalistas, ele destinava-se a ser representativo. Estes processos só estão abrindo a Amazônia para aprofundar a extração e a exploração em detrimento de projetos indígenas de "viver bem" que são levados adiante nas comunidades locais.

Kuper anuncia, com uma dose de melancolia, o "Retorno do Nativo" a políticas como a criação de discursos sem apoio no mundo "real". O problema com a tomada da política moderna como um ponto de partida modelo para entender a política baseada em diferentes visões de mundo é que corremos o risco de universalizar diferentes experiências sociais que são realmente vitais e que por isso, ao contrário, precisavam ser enfatizadas. Evitei concentrarme na “teoria cultural ocidental” que alguns líderes indígenas implantam em sua representação e, em vez disso, propus observar a ação política e os discursos colocados em prática pelos povos indígenas em suas vidas cotidianas que não são refratadas através de discursos indigenistas ou de ONG's. O conceito de Clastres de que "sociedades sem Estado" não são sociedades que ainda têm de se desenvolver politicamente - mas sociedades que resistiram ao surgimento da forma de poder político que gera o Estado - é útil nesse momento. Devemos considerar como práticas amazônicas podem nos conduzir a formas alternativas de pensar sobre a política, o sistema político e o social.

Um exame etnográfico mais detalhado do rizoma entre indígenas amazônicos ilumina práticas políticas que não são visíveis se observadas do exterior, mas que têm resultados que são absolutamente visíveis, mesmo que geralmente mal interpretados. Assim, quando um projeto de desenvolvimento fracassa as ONGs ou autoridades estaduais dizem "olhem para os índios, eles não têm a capacidade de gestão (capacidad de manejo), eles não fazem nada direito". Mas a razão pela qual estes projetos falham não é porque os ashaninka são fracassados, mas porque os rizomas estão exercendo uma força que, ao subverter a criação do Estado dentro de suas comunidades ou a imposição de hierarquias que os oprimiriam, subverte os próprios projetos.

Quando se trata de compreender as práticas políticas nas sociedades indígenas, há uma necessidade de olhar para além das formas de política que são mais notáveis do exterior. Mesmo que as práticas mais evidentes tenham nos dado algumas respostas, como o movimento político indígena, elas não são capazes de nos dar uma representação equilibrada das práticas políticas indígenas. Remodelando nossas ferramentas conceituais poderemos compreender as prioridades dos povos indígenas, abrindo espaço para analises dos atos políticos menos óbvios e das maneiras como estes são expressos nos confrontos e no envolvimento criativo com o Estado, as ONG's, as multinacionais e outros povos indígenas. É como se o que Count Basie disse sobre as notas musicais também se aplicasse à prática política indígena: "As notas que você não escuta são as que importam”. 


\section{BIBLIOGRAFIA}

AGENCIA ANDINA, 2012 : « Conap respalda reglamento de Ley de Consulta y pide apoyo de demás pueblos originarios. \ Disponible disponible sur Internet, <http://www.andina.com.pe/Espanol/noticia-conap-respaldareglamento-ley-consulta-y-pide-apoyo-demas-pueblos-originarios-400161.aspx> (consulté le 16 mai 2012).

ALBO, Xavier, 2004 : « Ethnic Identity and Politics in the Central Andes. The Cases of Bolivia, Ecuador and Peru », in Jo-Marie Burt et Philip Mauceri (dir.) Politics in the Andes : 17-37. University of Pittsburgh, Pittsburgh.

BLASER, Mario, 2009 : « The Threat of the Yrmo: The Political Ontology of a Sustainable Hunting Program ». American Anthropologist 111: 10-20.

BROWN, Michael, 1993 : «Facing the State, Facing the World: Amazonia's Native Leaders and the New Politics of Identity ». L'Homme 33(126-128) : 307-326.

CLASTRES, Pierre, 1987 : Society Against the State. Zone Books, New York.

COMISION DE LA VERDAD Y DE LA RECONCILIACION, 2003 : Informe Final. Perú.

CONKLIN, Beth, 2002 : « Shamans versus pirates in the Amazonian treasure chest ». American Anthropologist 104 : 1050-61.

CONKLIN, Beth, et Laura GRAHAM, 1995 : « The Shifting Middle Ground: Amazonian Indians and Eco-Politics »). American Anthropologist 97 : 695-710.

DE LA CADENA, Marisol, 2000 : Indigenous Mestizos : The Politics of Race and Culture in Cuzco, Peru, 19191991. Duke University Press, Durham.

DE LACADENA, Marisol, 2010 : «Indigenous cosmopolitics in the Andes: Conceptual reflections beyond "politics” ». Cultural Anthropology 25(2): 334-370.

DELEUZE, Gilles and Félix GUATTARI, 1988 : A Thousand Plateaus : Capitalism and Schizophrenia. Athlone, London.

DENEVAN, William, 1974 : « Campa Subsistence in the Gran Pajonal, Eastern Peru ». Geographical Review 61 : 496-518.

DOMBROMSKI, Kirk, 2002 : «The praxis of indigenism and Alaska Native Timber politics ». American Anthropologist $104: 1062-73$.

GLEDHILL, John, 2000 : Power and its Disguises: Anthropological Perspectives on Politics. London: Pluto Press.

GOW, Peter, 1989 : « The Perverse Child: Desire in a Native Amazonian Subsistence Economy ». Man 24 : 567-582. 
GOW, Peter, 2000 : « Helpless - The Affective Preconditions of Piro Social Life », in Joanna Overing et Alan Passes (dir.) The Anthropology of Love and Anger : The Aesthetics of Conviviality in Native Amazonia : 46-63. London, Routledge.

GOW, Peter, 2001 : An Amazonian Myth and its History. Oxford: Oxford University Press.

GRAEBER, David, 2001 : Toward an Anthropological Theory of Value: The Flase Coin of Our Own Dreams. New York : Palgrave.

GREEN, Shane, 2006 : « Getting over the Andes: The Geo-Eco-Politics of Indigenous movements in Peru’s TwentyFirst Century Inca Empire ». Journal of Latin American Studies 38(2): 327-354.

HALE, Charles, 2002 : «Does Multiculturalism Menace?: Governance, Cultural Rights and the Politics of Identity in Guatemala ». Journal of Latin American Studies 14(3) : 485-524.

HALE, Charles, 2004 : « Rethinking Indigenous Politics in the Era of the 'Indio Permitido ». NACLA Report on the Americas, September/October: 16-21.

JACKSON, Jean, 1995 : « Culture, Genuine and Spurious: The Politics of Indianness in the Vaupes, Columbia ». American Ethnologist 22(1) : 3-27.

KILLICK, Evan, 2007 : « Autonomy and Leadership: Political Formations among the Ashéninka of Peruvian Amazonia ». Ethnos 72(4): 461-482.

KUPER, Adam, 2003: « The Return of the Native ». Current Anthropology 44(3) : 389-402.

LI, Tania, 2000: «Articulating Indigenous Identity in Indonesia: Resource Politics and the Tribal Slot ». Comparative Studies in Society and History 42(1) : 149-179.

MINDE, Henry (dir.), 2008 : Indigenous Peoples : Self-determination, Knowledge, Indigeneity. Eburon Delft, Delft.

NIEZEN, Ronald, 2003 : The Origins of Indigenism. Human Rights and the Politics of Identity. University of California Press, Berkeley.

OVERING, Joanna, 2008 : « The Backlash to Decolonizing Intellectuality ». Anthropology and Humanism 31(1) : $11-40$.

OVERING, Joanna et Alan PASSES, 2000 (dirs.) : The Anthropology of Love and Anger: The Aesthetics of Conviviality in Native Amazonia. Routledge, London.

ORDINAIRE, Olivier, 1988 : Del Pacifico al Atlantico y Otros Escritos. IFEA, Lima.

PASSES, Alan, 2004 : «The place of politics: powerful speech and women speakers in everyday Pa'ikwené (Palikur) life ». Journal of the Royal Anthropological Institute $10(1): 1-18$. 
POVINELLI, Elizabeth, 2002 : The Cunning of Recognition : Indigenous Alterities and the Making of Australian Multiculturalism. Duke University Press, Durham.

ROSENGREN, Dan, 2003 : In the eyes of the beholder: leadership and the social construction of power and dominance among the Matsigenka of the Peruvian Amazon. Goteborgs Etnografiska Museum, Gothenburg.

ROSENGREN, Dan, 2003 : «The Collective Self and the Ethnopolitical Movement: "rhizomes" and "taproots" in the Amazon ». Identities : Global Studies in Culture and Power 10 : 221-240.

RUBENSTEIN, Steven, 2004 : « Steps to a Political Ecology of Amazonia ». Tipiti 2(2) : 131-176.

RUEDAS, Javier, 2004 : «History, Ethnography, and Politics in Amazonia: Implications of Diachronic and Synchronic Variability in Marubo Politics ». Tipiti 2(1)

SAID, Edward, 1978: Orientalism. Routledge, London.

SANTOS-GRANERO, Fernando, 1986a : «Power, Ideology and the Ritual of Production in Lowland South America ». Man 21(4) : 657-679.

SANTOS-GRANERO, Fernando, 1986b : «The moral and social aspects of equality amongst the Amuesha of Central Peru ». Journal de la Societe des Americanistes 72 : 107-113.

SANTOS-GRANERO, Fernando, 2000 : « The Sisyphus Syndrome or the Struggle for Conviviality in Native Amazonia », in Joanna Overing et Alan Passes (dir.) The Anthropology of Love and Anger : The Aesthetics of Conviviality in Native Amazonia : 268-287. London, Routledge.

SANTOS-GRANERO, Fernando, 2009 : « Hybrid Bodyscapes: A Visual History of Yanesha Patterns of Cultural Change ». Current Anthropology 50(4): 477-512.

SARMIENTO BARLETTI, Juan Pablo, 2011 : Kametsa Asaiki: The Pursuit of the 'Good Life' in an Ashaninka Village (Peruvian Amazonia). PhD Thesis, University of St Andrews.

SERVINDI, 2012 : « Perú: “La Ley de Consulta no tiene el espíritu del Convenio 169”». Disponible disponible sur Internet, $<$ http://servindi.org/actualidad/59926>.

VEBER, Hanne, 2009 : Historias para nuestro futuro: Narraciones autobiográficas de líderes Asháninka y Ashéninka de la Selva Central del Perú. IWGIA: Copenhagen.

VILAÇA, Aparecida, 2002 : « Making Kin Out Of Others In Amazonia ». Journal of the Royal Anthropological Institute 8(2) : 347-365.

VILAÇA, Aparecida, 2005 : «Chronically Unstable Bodies: Reflections on Amazonian Corporalities». Journal of the 
Royal Anthropological Institute 11(3) : 445-464.

VIVEIROS DE CASTRO, Eduardo, 1998 : «Cosmological Deixis and Amerindian Perspectivism ». Journal of the Royal Anthropological Institute 4(3) : 469-488.

VIVEIROS DE CASTRO, Eduardo, 2001 : « GUT Feelings aboutAmazonia: Potential affinity and the construction of sociality », in Laura Rival and Neil Whitehead (dir.) Beyond the Visible and the Material : 19-44. Oxford: Oxford University Press.

WARREN, Kay, et Jean Jackson (dirs.), 2002 : Indigenous Movements, Self-Representation, and the State in Latin America. University of Texas Press : Austin.

WWF PERU, 2008 : « Consolidando el manejo forestal comunitario ». Disponible sur Internet, <http:/peru.panda. org/?175223/Consolidando-el-manejo-forestal-comunitario>. (Consulté le 16 mai 2012).

YASHAR, Deborah, 2005 : Contesting Citizenship in Latin America: The Rise of Indigenous Movements and the Postliberal Challenge. Cambridge University Press, Cambridge. 